\title{
Rational Design of a Potent Pan-Pim Kinases Inhibitor with a Rhodanine-Benzoimidazole Structure
}

\author{
YUICHI SAWAGUCHI, RYUTA YAMAZAKI, YUKIKO NISHIYAMA, TOSHIO SASAI, MASAYUKI MAE, \\ ATSUHIRO ABE, TAKASHI YAEGASHI, HIROYUKI NISHIYAMA and TAKESHI MATSUZAKI \\ Yakult Central Institute, Yakult Honsha Co., Ltd., Tokyo, Japan
}

\begin{abstract}
Background/Aim: The serinelthreonine Pim kinases are overexpressed in various types of solid carcinomas and hematological malignancies, and contribute to regulating cell-cycle progression and cell survival. The aim of this study was to discover a novel pan-Pim kinases inhibitor with potent anti-proliferative activities against cancer cell lines. Materials and Methods: We screened a panel of small molecule compounds for their ability to inhibit Pim-1 kinase activity, and the hit compound was optimized using the docking analysis to Pim-1. We evaluated kinase-inhibition activities of the rationally-designed compound against Pim-1, 2, 3 and another five kinases. Furthermore, in order to characterize the cellular activities, both solid and hematological cancer cell lines treated with the compound were subjected to antiproliferative assay, western blotting, FACS and apoptosis assays. Results: We discovered a pan-Pim kinases inhibitor, compound 1, with a rhodanine-benzylidene structure via Pim1 inhibitor screening. Using docking analysis of compound 1 and Pim-1, we optimized it and found a potent-and selectivePim kinases inhibitor, compound 2, with a rhodaninebenzoimidazole structure. Compound 2 inhibited Pim-1, 2, 3 with $I_{50}$ values of 16,13 , and $6.4 \mathrm{nM}$, respectively, and suppressed proliferation of solid and hematological cancer cell lines at submicromolar concentrations. In both types of cell lines, compound 2 inhibited phosphorylation of Pim signaling substrates and cell-cycle progression and induced apoptosis. Conclusion: We identified a pan-Pim kinases inhibitor, compound 2, with a rhodanine-benzoimidazole structure. Our data suggest that compound 2 can serve as a lead to novel anticancer agents, effective in the treatment of both solid carcinomas and hematological malignancies.
\end{abstract}

Correspondence to: Yuichi Sawaguchi, Yakult Central Institute, Yakult Honsha Co., Ltd. 5-11 Izumi, Kunitachi-shi, Tokyo, 1868650, Japan. Tel: +81 425778960, Fax: +81 425773020, e-mail: yuichi-sawaguchi@yakult.co.jp

Key Words: Pim kinases inhibitors, rhodanine-benzylidene, rhodanine-benzoimidazole, docking analysis, anticancer activity.
Pim kinases are serine/threonine kinases that phosphorylate several regulators of cell cycle progression and apoptosis, and thereby promote cell survival and proliferation (1). Pim kinase family members are composed of Pim-1, 2, 3, which are highly homologous to each other (2). Although Pim-1, 2, 3 are distributed in different tissues, they have similar functions (3).

Pim-1, 2, 3 phosphorylate and inactivate Bad protein, a member of the apoptotic protein Bcl-2 family, and therefore suppress apoptosis (4-6). Pim-1, 2 have been shown to phosphorylate the $4 \mathrm{E}-\mathrm{BP} 1$ protein, a repressor of mRNA translation, dissociate it from eukaryotic translation initiation factor $4 \mathrm{E}$, and promote cell growth (7, 8). Pim-1 phosphorylates Cdc25A, a positive regulator of cell cycle, and enhances its phosphatase activity (9). Also, Pim-1 phosphorylates and inactivates $\mathrm{p} 21^{\mathrm{Cip} 1 / \mathrm{WAF} 1}$, a negative regulator of cell cycle (10). As a result, Pim-1 is thought to accelerate the cell cycle from the $G_{1}$ to $S$ phase.

As stated above, Pim kinases regulate many factors involved in cell survival and proliferation, are therefore considered to contribute to diseases characterized by abnormal cell proliferation including cancer. It has been reported that Pim kinases are associated with the progression of various types of cancer, e.g. solid carcinomas including prostate cancer and hematological malignancies including acute myeloid leukemia (AML) (11-17). Moreover, Pim kinases were suggested to be involved in angiogenesis and anticancer drug resistance in chemotherapy $(18,19)$. Given these facts, Pim kinases inhibitors were considered as new targets for anticancer therapy. Pim1-, 2-, 3-selective inhibitor PIM447 and INCB053914 are now in Phase I and I/II clinical studies, respectively, but there is no other Pim kinases inhibitor in clinical development. Herein, we report the discovery of a Pim-1, 2, 3 inhibitor with a rhodanine-benzylidene structure via Pim-1 inhibitor screening. In addition, we optimized it using docking analysis with Pim-1, and found a Pim-1, 2, 3 selective inhibitor with a rhodanine-benzoimidazole structure, cytotoxic both to solid and hematological cancer cell lines. 
a<smiles>CCOc1cc(/C=C2\SC(=S)NC2=O)ccc1O</smiles>

b

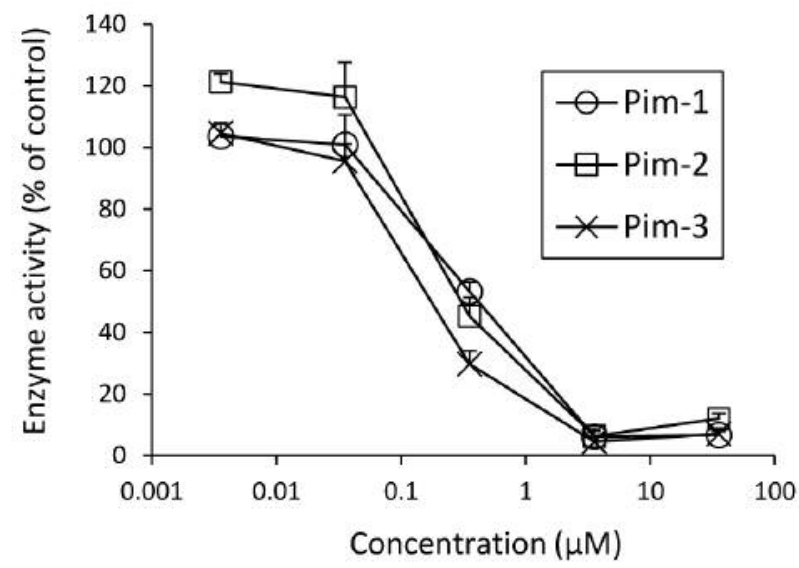

Figure 1. Structure and biochemical activities of compound 1, (a) Chemical structure of compound 1.(b) In vitro kinase assays of Pim-1,2, 3 with varying concentrations of compound $\mathbf{1}$.

\section{Materials and Methods}

Materials. Compound $\mathbf{1}$ and compound $\mathbf{2}$ were synthesized in house and dissolved in dimethylsulfoxide (DMSO).

Antibodies. The following antibodies were used for immunoblotting: Phospho-4E-BP1 (Thr37/46) (\#9459, Cell Signaling Technology, Danvers, MA, USA), 4E-BP1 antibody (\#9452, Cell Signaling Technology, Danvers, MA, USA), Antiphospho-Bad (pSer112) (\#SAB4300050, Sigma-Aldrich, St. Louis, MO, USA), Anti-BAD, antibody produced in rabbit (\#SAB3500336, Sigma-Aldrich, St. Louis, MO, USA), Monoclonal Anti- $\alpha$-tubulin produced in mouse (\#T9026, SigmaAldrich, St. Louis, MO, USA).

In vitro kinase activity assay. The inhibition ratio of test compounds for Pim-1, 2, 3 kinases were determined using a modified FRET-based Z'-LYTE kinase assay kit-Ser/Thr 7 peptide (Thermo Fisher Scientific, Madison, WI, USA). The reactions were carried out in 384-well plates with $10 \mu \mathrm{L}$ reaction volume per well containing $1 \mu \mathrm{M}$ Ser/Thr 7 peptide $\mathrm{P}$ substrate in $50 \mathrm{mM}$ HEPES $\mathrm{pH} 7.5,0.01 \%$ BRIJ-35, $10 \mathrm{mM} \mathrm{MgCl}_{2}, 1 \mathrm{mM}$ EGTA and appropriate amount of kinases (Pim-1: $0.03 \mu \mathrm{g} / \mathrm{mL}$, Pim-2: $0.2 \mu \mathrm{g} / \mathrm{mL}$, Pim-3: $0.2 \mu \mathrm{g} / \mathrm{mL}$ ) with test compounds. The final reaction concentrations of ATP were 400,5 and $100 \mu \mathrm{M}$ for Pim$1,2,3$, respectively. After $1 \mathrm{~h}$ incubation, reactions were developed and terminated, and fluorescence ratios were calculated as per the manufacturer's protocol.

AMPK $\alpha 1$, ERK2, v-SRC, FGFR1, and EGFR kinase activities were performed using an electrophoretic mobility shift assay. Compound 2 was diluted with assay buffer (20 mM HEPES, pH7.5, $0.01 \%$ Triton X-100, $2 \mathrm{mM}$ DTT) and added to 384-well plates. Peptide substrates and ATP in assay buffer were added to the wells. After that, each kinase prepared in assay buffer was also added to the wells and mixed to start the reaction. After a period of incubation at room temperature, the reaction was stopped by
Termination Buffer (QuickScout Screening Assist MSA; Carna Biosciences, Hyogo, Japan). Finally, the plate was put on a LabChip 3000 system (Caliper Life Sciences, Hopkinton, MA) and a droplet of the reaction mixture was applied for electrophoretic separation in the chips of the machine. Then the enzyme conversion data was read out for analysis.

Cells and cell cultures. All cell lines were obtained from American Type Culture Collection (Manassas, VA) and cultured in RPMI1640 medium (Thermo Fisher Scientific, Waltham, MA, USA) with $10 \%$ $(\mathrm{v} / \mathrm{v})$ fetal bovine serum (FBS; Sigma-Aldrich, Danvers, MA, USA) at $37^{\circ} \mathrm{C}$ in $5 \% \mathrm{CO}_{2}$.

Cytotoxicity assay for cell survival. A549, HCT116, PC-3 or MV4-11 cells were seeded in 96-well plates and test drugs were added to the cultures at several concentrations. After $96 \mathrm{~h}$, cell viabilities were measured with WST-8 (Dojindo, Kumamoto, Japan) and the $\mathrm{IC}_{50}$ concentration of each test compound was calculated.

Docking analysis of compound 1 to Pim-1. All in silico works including docking analyses were performed using MOE software (MOE ver.2015, Chemical Computing Group Inc., Montreal, Canada). The three-dimensional structure of Pim-1 was obtained from the protein data bank (PDB code 3F2A). The Pim-1 structure was hydrogenated using the Protonate $3 \mathrm{D}$ module. After partial charges were assigned using Merck Molecular Force Field 94x (MMFF94X) (20), hydrogen atoms were minimized. The Alpha Site Finder module was used for definition of a ligand-binding site targeting the ATP binding site of Pim-1.

In the docking analysis using the MOE-dock module, compound 1 conformation previously generated by the stochastic search method was posed on the binding site. The docked poses were scored by the London $\mathrm{dG}$ scoring function. The top 30 poses were further optimized by the GBVI/WSA dG scoring function with the Generalized Born/Volume Integral solvation model (21), and the top 5 poses were finally output. 
Immunoblots. Cells were plated overnight and then treated with test compounds in serum-starved medium for $4 \mathrm{~h}$. Cells were lysed in solubilization buffer [10 mM Tris- $\mathrm{HCl}(\mathrm{pH} 7.4), 0.1 \%$ (w/v) NP-40, $0.1 \%(\mathrm{w} / \mathrm{v})$ sodium deoxycholate, $0.1 \%(\mathrm{w} / \mathrm{v})$ SDS, $0.15 \mathrm{M} \mathrm{NaCl}$, $1 \mathrm{mM}$ EDTA, $10 \mu \mathrm{M}$ aprotinin] with phosphatase inhibitor cocktails (Nakarai Tesque, Kyoto, Japan), and subjected to SDS-PAGE using $15 \%(\mathrm{w} / \mathrm{v})$ gels under reducing conditions. The separated proteins were electrotransferred to Immobilon transfer membranes (Merck Millipore, Billerica, MA, USA). Then, each membrane was reacted with primary antibodies, which were subsequently complexed with appropriate horseradish peroxidase-conjugated secondary antibodies. Signal was detected using the ECL Western Blotting Detection System (GE Healthcare Life Sciences, Buckinghamshire, UK) and protein expression was quantified with a LAS-3000 Luminescent Image Analyzer (GE Healthcare Life Sciences).

Cell-cycle analysis. Cells were treated with test compounds for 24 h. After treatment, cells were fixed and stained with propidium iodide using the Cell Cycle Phase Determination kit (Cayman Chemical, Ann Arbor, MI, USA) and analyzed by the Guava EasyCyte $^{\mathrm{TM}}$ Plus System (Merck Millipore).

Caspase-3/7 activity assay. Cells were grown in 96-well plates and treated with test compounds for $24 \mathrm{~h}$. The Caspase-Glo $3 / 7$ reagent was then added to each well and incubated for $1 \mathrm{~h}$. Caspase-3/7 activity was detected using the Caspase-Glo 3/7 Assay System (Promega, Madison, WI) and conducted as per the manufacturer's protocol.

\section{Results}

Identification of a novel Pim kinases inhibitor, compound 1. To identify Pim-1 inhibitors, we screened a panel of small molecule compounds for their ability to inhibit Pim-1 kinase activity. Subsequently, (Z)-5-(3-ethoxy-4-hydroxybenzylidene)-2-thioxothiazolidin-4-one (compound 1), a molecule containing a rhodanine group, was found as an inhibitor of Pim-1 (Figure 1a). Compound 1 inhibited Pim-1, 2, 3 kinase activities in dose-dependent manners, with $\mathrm{IC}_{50}$ values of $0.42,0.31$, and $0.17 \mu \mathrm{M}$, respectively (Figure $1 \mathrm{~b}$ ).

Optimization of compound 1 using the computational docking to Pim-1. To rationally modify compound 1 into a potent Pim-1, 2, 3 inhibitor, we employed the docking analysis of the compound 1-Pim-1 complex, because Pim-1, 2, 3 share a high-level sequence identity in their kinase domains $(3,22)$. As a result of the docking analysis it was found that the $\mathrm{NH}$ and carbonyl of compound 1 may be interacting with Lys67 and Asp186 in Pim1 and there may be Asp128 and Glu171 on the lower side of the 3-ethoxy-4-hydroxyphenyl group (Figure 2a). Based on these results, we designed compound 2 , which had a $1 \mathrm{H}-$ benzo[d]imidazole ring instead of 3-ethoxy-4-hydroxyphenyl group, and methylpierazine as an aliphatic amine through the phenyl group as a linker. The binding model of compound 2 within the Pim-1 ATP is shown in Figure 2b. In this proposed binding model of compound 2, the carboxyl group of Asp128 and/or Glu171 was deemed an appropriate position to interact
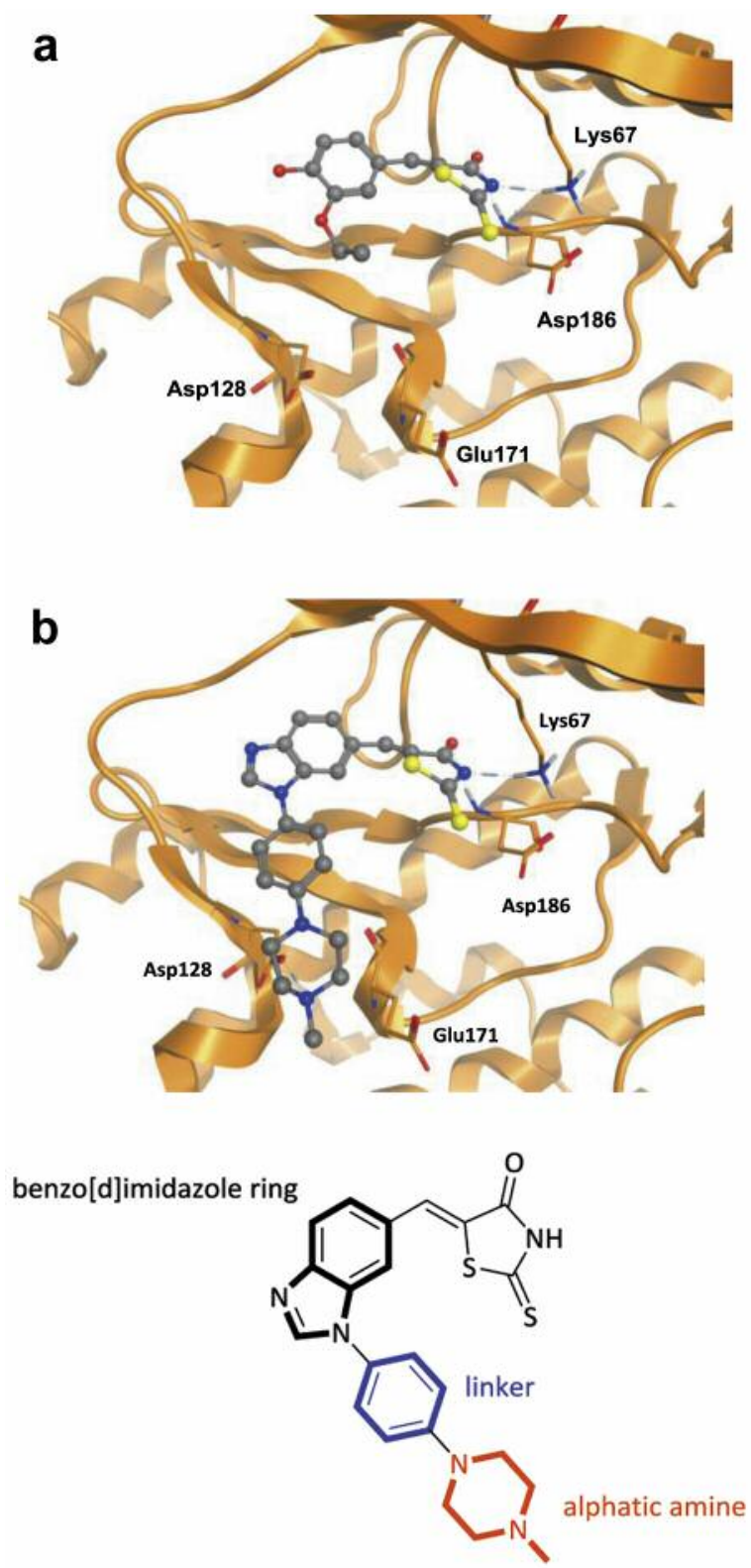

compound $\mathbf{2}$

Figure 2. Optimization of compound 1 into compound 2 to improve the Pim kinases-inhibitory activity. (a) Docking model of compound 1 to the ATP binding site of Pim-1. Compound 1 is shown in a ball-and-stick representation. The hydrogen bonds between compound 1 and Pim-1 residues are indicated with broken lines. (b) Design of novel 1,3thiazolidine-2,4-diones (compound 2) and docking model to the ATP binding site of Pim-1. The hydrogen bonds between compound 2 and Pim-1 residues are indicated with broken lines.

with methylpiperazine as an aliphatic basic amine. Consequently, compound $\mathbf{2}$ was predicted to improve kinase potency due to the possible additional interactions of the polar groups with Asp128 and/or Glu171. 
a

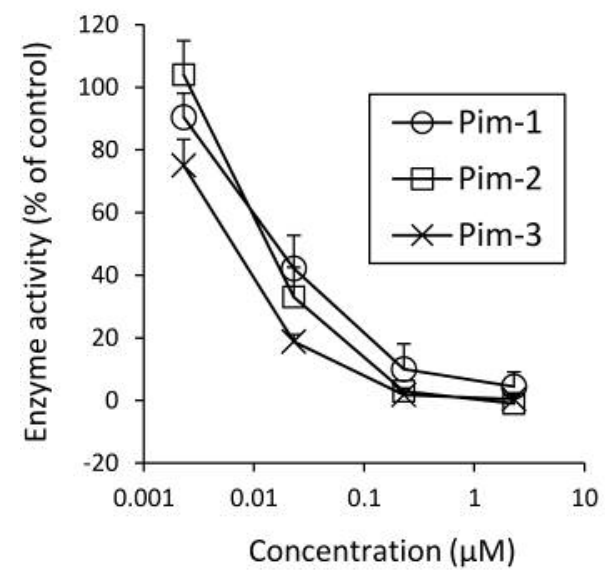

b

\begin{tabular}{cc}
\hline & $\mathrm{IC}_{50}(\mu \mathrm{M})$ \\
\hline Pim-1 & 0.016 \\
Pim-2 & 0.013 \\
Pim-3 & 0.0064 \\
AMPKa1 & 1.1 \\
ERK2 & $>10$ \\
V-SRC & $>10$ \\
FGFR1 & $>10$ \\
EGFR & $>10$ \\
\hline
\end{tabular}

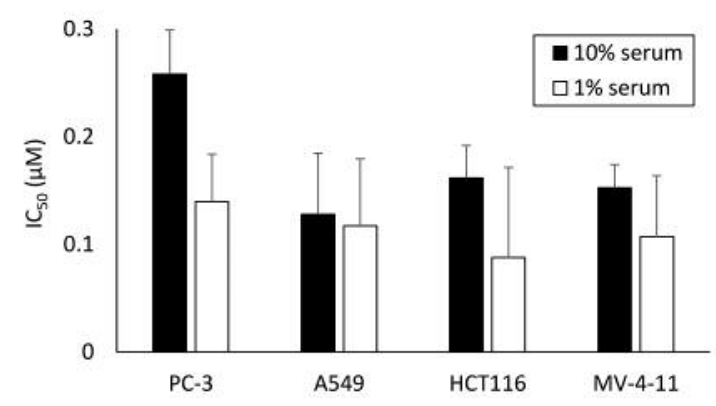

Figure 3. Biochemical activities of compound 2. (a) In vitro kinase assays of Pim-1, 2, 3, AMPKa1, ERK2, v-SRC, FGFR1, and EGFR with varying concentrations of compound 2. Kinase activities of Pim-1,2, 3 in each concentration of compound 2 are shown as a graph, and IC ${ }_{50}$ values for each kinase are listed in a table. (b) Inhibitory effects of compound 2 on cancer cell proliferation. The indicated cell lines were treated with compound 2 in 10\% serum-containing medium and cell viability was analyzed by MTT assay. (c) Inhibitory effects of compound 2 on cancer cell proliferations under $10 \%$ or $1 \%$ serum condition. In $10 \%$ or $1 \%$ serum-containing medium A549, HCT116, PC-3, or MV-4-11 cells were treated with DMSO or compound 2, and cell viability was analyzed by MTT assay. Data are represented as mean $I C_{50}$ values obtained from three independent experiments.

Biochemical activity of the pan-Pim kinases inhibitor, compound 2. Compound 2 inhibited Pim-1, 2, 3 kinase activities in dose-dependent manners, with $\mathrm{IC}_{50}$ values of 16 13, and $6.4 \mathrm{nM}$, respectively (Figure 3a). As an index of kinase inhibition specificity, we measured the effects of compound 2 against two kinds of serine/threonine kinases (AMPK $\alpha$ and ERK2) and three kinds of tyrosine kinases (vSRC, FGFR1, and EGFR) (Figure 3a, right). Then, the $\mathrm{IC}_{50}$ value for AMPK $\alpha$ was $1.1 \mu \mathrm{M}$, and those for the other four kinases were over $10 \mu \mathrm{M}$. In $10 \%$ serum condition, compound 2 exerted antiproliferative activity against PC-3, A549, HCT116, and MV-4-11 cells with $\mathrm{IC}_{50}$ values of $0.26,0.13$, 0.16 , and $0.15 \mu \mathrm{M}$, respectively (Figure $3 \mathrm{~b}$ ). In a previous report, it was shown that the cellular activities of benzylidenethiazolidine inhibitors of Pim-1 might be affected by serum in the culture medium (24). Therefore, in order to show the influence of serum in the culture medium against the activity of compound $\mathbf{2}$, we measured the antiproliferative activity in $1 \%$ serum medium (Figure $3 \mathrm{~b}$ ). As a result, the $\mathrm{IC}_{50}$ values for each cell line in the $1 \%$ serum condition were $0.13,0.12$, 0.088 , and $0.11 \mu \mathrm{M}$, respectively, which were almost equal to those in the $10 \%$ serum condition.

Cellular activity of compound 2. PC-3 and MV-4-11 cells were treated with compound $\mathbf{2}$ to evaluate the effects on phosphorylation of Pim kinases substrates 4E-BP and Bad (Figure 4). Compound 2 dose-dependently decreased phosphorylation on $4 \mathrm{E}-\mathrm{BP}$ from 0.3 to $10 \mu \mathrm{M}$ in both cell lines, and on Bad from 1 to $10 \mu \mathrm{M}$ in PC-3 cells.
With a view to revealing the biological events induced by compound 2, we treated PC-3 and MV-4-11 cells with compound 2 for $24 \mathrm{~h}$ and assessed the effects on cell cycle progression (Figure 5a). In PC-3 cells, compound 2 dosedependently increased the percentages of cells at the $\mathrm{G}_{1}$ phase from 44\% (DMSO) to 57 and 55\% (3, and $10 \mu \mathrm{M}$ compound 2, respectively). Similarly, in MV-4-11 cells the percentages of cells at the $\mathrm{G}_{1}$ phase were 68,70 , and $88 \%$ in the cells treated with DMSO, 1 , and $3 \mu \mathrm{M}$ compound 2 , respectively. These results revealed that compound $\mathbf{2}$ induced cell cycle arrest at the $G_{1}$ phase in both cell lines. We next evaluated apoptosis of these two cell lines induced by the treatment of compound 2 for 24 h (Figure 5b). Compound 2 induced apoptosis of both PC-3 and MV-4-11 cells in doses of 1 to $10 \mu \mathrm{M}$ and 0.3 to $3 \mu \mathrm{M}$, respectively, as detected on the basis of caspase- $3 / 7$ activation.

\section{Discussion}

We conducted Pim-1 inhibitor screening and identified the inhibitor compound $\mathbf{1}$ with a rhodanine-benzylidene structure, which showed submicromolar $\mathrm{IC}_{50}$ values for Pim1, 2, 3 activities. Then, using the computational docking analysis of compound $\mathbf{1}$ and Pim-1, we identified compound $\mathbf{2}$, with a rhodanine-benzoimidazole structure. Compound $\mathbf{2}$ inhibited all Pim-1, 2, 3 activities with $\mathrm{IC}_{50}$ values of singleto double-digit nanomolars. Therefore, it is suggested that compared to compound $\mathbf{1}$, compound $\mathbf{2}$ has a higher affinity to Pim kinases, probably because of extensive interaction. In 
a

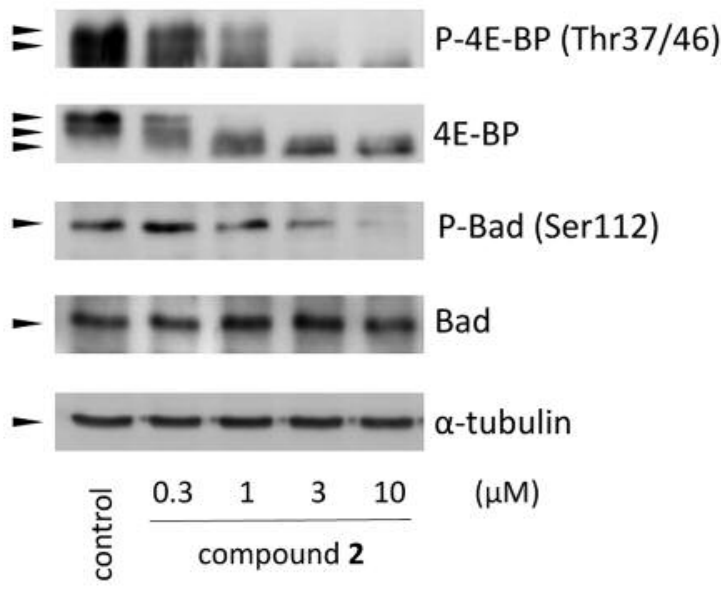

b

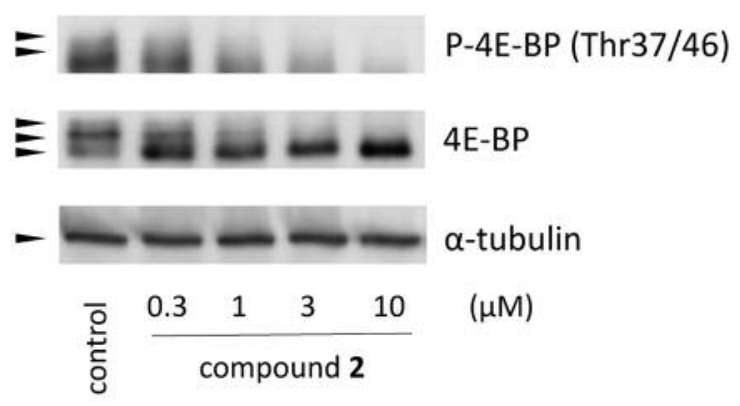

Figure 4. Immunoblot analysis of phosphorylation on Pim kinases substrates in PC-3 and MV-4-11 cells PC-3 (a) and MV-4-11 (b) cells were treated with DMSO alone or compound 2 for 4 hours, then harvested and lyzed. The expressions of phosho-4E-BP (Thr37/46) and total $4 E-B P$ in both cell lines, and those of phosho-Bad (Ser112) and total Bad in PC-3 cells, were analyzed by immunoblot. Alpha-tubulin was used as a loading control.

a

PC-3

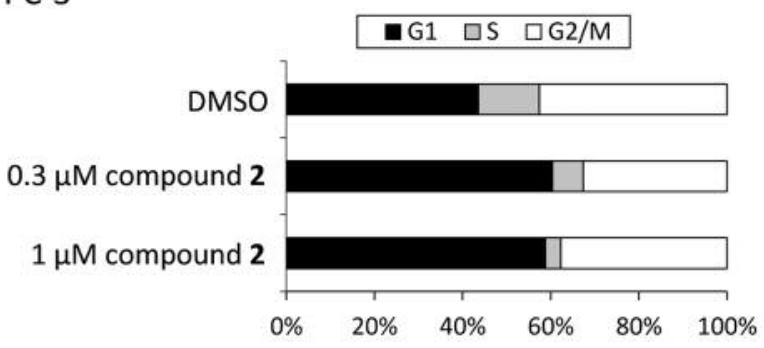

b

PC-3

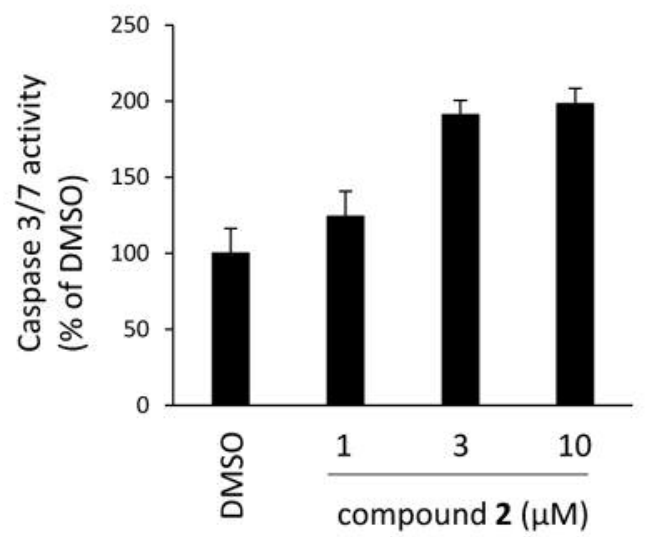

MV-4-11

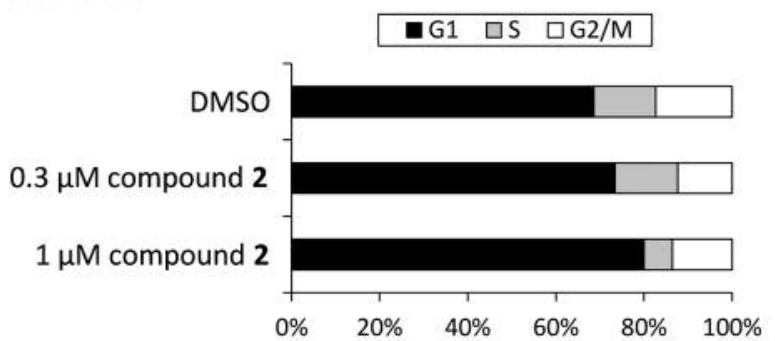

MV-4-11

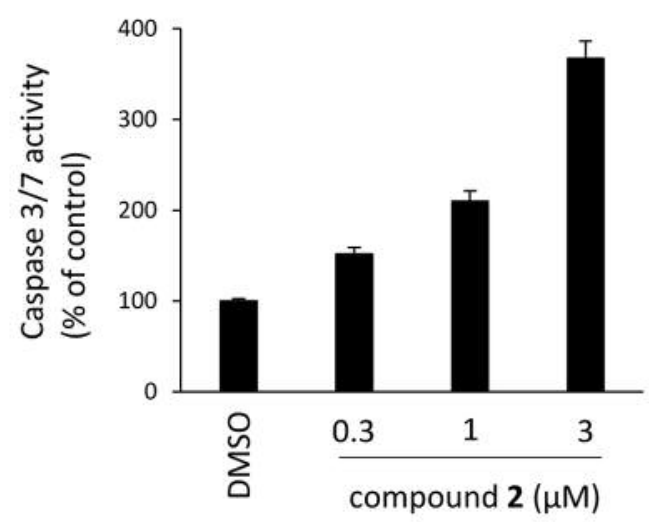

Figure 5. Effects of compound 2 on cell cycle progression and apoptosis induction (a) PC-3 and MV-4-11 cells were incubated with DMSO or compound 2 for $24 \mathrm{~h}$. Then, cell cycle was analyzed by flow cytometry after propidium iodide staining. (b) Caspase3/7 activities were measured after treatment with increasing doses of compound 2 for $24 \mathrm{~h}$. 
addition, an evaluation of inhibition activities of another five kinases suggested the high selectivity of compound $\mathbf{2}$ as a Pim-1, 2, 3 inhibitor. In a $10 \%$ serum condition, compound 2 exhibited submicromolar $\mathrm{IC}_{50}$ values against the proliferations of both solid and hematological cancer cell lines. Furthermore, in a comparison of the anti-proliferative activities between the $10 \%$ and $1 \%$ serum conditions, the cellular activity of compound $\mathbf{2}$ was almost independent of its binding ability to serum protein. In both PC-3 and MV4-11 cells compound 2 decreased the phosphorylation on Pim kinases substrates in dose-dependent manners from 0.3 to $10 \mu \mathrm{M}$. In almost the same concentration range, it induced cell-cycle arrest at the $\mathrm{G}_{1}$ phase and apoptosis against these cell lines. These results suggest compound $\mathbf{2}$ inhibited the activities of Pim kinases in cells and consequently induced biological events concerning Pim kinases signaling.

PIM447, INCB053914, AZD1208, and SGI-1776 are the only Pim kinase inhibitors to enter clinical trials, and all have exhibited antitumor activities against hematological malignancies models in preclinical studies (23-26). Among them, AZD1208 and SGI-1776 also displayed in vivo activities against a solid cancer xenograft model $(27,28)$. Despite these notable facts, clinical studies of these two compounds were suspended because of their poor tolerability. Therefore, both in the treatment of solid carcinomas and hematological malignancies, compounds having a rhodanine and benzoimidazole structure as the mother nucleus are potential novel anticancer agents as pan-Pim kinases inhibitors.

\section{References}

1 Amaravadi $\mathrm{R}$ and Thompson $\mathrm{CB}$ : The survival kinases Akt and Pim as potential pharmacological targets. J Clin Invest 115: 2618-2624, 2005.

2 Saurabh K, Scherzer MT, Shah PP, Mims AS, Lockwood WW, Kraft AS and Beverly LJ: The PIM family of oncoproteins: small kinases with huge implications in myeloid leukemogenesis and as therapeutic targets. Oncotarget 5: 8503-8514, 2014.

3 Eichmann A, Yuan L, Bréant C, Alitalo K and Koskinen, PJ: Developmental expression of pim kinases suggests functions also outside of the hematopoietic system. Oncogene 19: 1215$1224,2000$.

4 Aho TL, Sandholm J, Peltola KJ, Mankonen HP, Lilly M and Koskinen PJ: Pim-1 kinase promotes inactivation of the proapoptotic Bad protein by phosphorylating it on the Ser112 gatekeeper site. FEBS Lett 571: 43-49, 2004.

5 Li YY, Popivanova BK, Nagai Y, Ishikura H, Fujii C and Mukaida N: Pim-3, a proto-oncogene with serine/threonine kinase activity, is aberrantly expressed in human pancreatic cancer and phosphorylates bad to block bad-mediated apoptosis in human pancreatic cancer cell lines. Cancer Res 66: 6741$6747,2006$.

6 Yan B, Zemskova M, Holder S, Chin V, Kraft A, Koskinen PJ and Lilly M: The PIM-2 kinase phosphorylates BAD on serine 112 and reverses BAD-induced cell death. J Biol Chem 278: 45358-45367, 2003.
7 Fox CJ, Hammerman PS, Cinalli RM, Master SR, Chodosh LA and Thompson CB: The serine/threonine kinase Pim-2 is a transcriptionally regulated apoptotic inhibitor. Genes Dev 17: 1841-1854, 2003.

8 Chen WW, Chan DC, Donald C, Lilly MB and Kraft AS: Pim family kinases enhance tumor growth of prostate cancer cells. Mol Cancer Res 3: 443-451, 2005.

9 Mochizuki T, Kitanaka C, Noguchi K, Muramatsu T, Asai A and Kuchino Y: Physical and functional interactions between Pim-1 kinase and Cdc25A phosphatase. Implications for the Pim-1mediated activation of the c-Myc signaling pathway. J Biol Chem 274: 18659-18666, 1999.

10 Wang Z, Bhattacharya N, Mixter PF, Wei W, Sedivy J and Magnuson NS: Phosphorylation of the cell cycle inhibitor p21Cip1/WAF1 by Pim-1 kinase. Biochim Biophys Acta 1593: 45-55, 2002.

11 Hammerman PS, Fox CJ, Birnbaum MJ and Thompson CB: Pim and Akt oncogenes are independent regulators of hematopoietic cell growth and survival. Blood 105: 4477-4483, 2005.

12 Dhanasekaran SM, Barrette TR, Ghosh D, Shah R, Varambally S, Kurachi K, Pienta KJ, Rubin MA and Chinnaiyan AM: Delineation of prognostic biomarkers in prostate cancer. Nature 412: 822-826, 2001.

13 Ellwood-Yen K, Graeber TG, Wongvipat J, Iruela-Arispe ML, Zhang J, Matusik R, Thomas GV and Sawyers CL: Myc-driven murine prostate cancer shares molecular features with human prostate tumors. Cancer Cell 4: 223-238, 2003.

14 Santio NM, Salmela M, Arola H, Eerola SK, Heino J, Rainio EM and Koskinen PJ: The PIM1 kinase promotes prostate cancer cell migration and adhesion via multiple signalling pathways. Exp Cell Res 342: 113-124, 2016.

15 Popivanova BK, Li YY, Zheng H, Omura K, Fujii C, Tsuneyama $\mathrm{K}$ and Mukaida N: Proto-oncogene, Pim-3 with serine/threonine kinase activity, is aberrantly expressed in human colon cancer cells and can prevent Bad-mediated apoptosis. Cancer Sci 98: 321-328, 2007.

16 Amson R, Sigaux F, Przedborski S, Flandrin G, Givol D and Telerman A: The human protooncogene product $\mathrm{p} 33 \mathrm{pim}$ is expressed during fetal hematopoiesis and in diverse leukemias. Proc Natl Acad Sci USA 86: 8857-8861, 1989.

17 Nieborowska-Skorska M, Hoser G, Kossev P, Wasik MA and Skorski T: Complementary functions of the antiapoptotic protein A1 and serine/threonine kinase pim-1 in the BCR/ABL-mediated leukemogenesis. Blood 99: 4531-4539, 2002.

18 Zhang P, Wang H, Min X, Wang Y, Tang J, Cheng J, Li D, Chen $\mathrm{X}$, Cheng $\mathrm{F}$, Wang $\mathrm{N}$ and Yang $\mathrm{H}$ : Pim-3 is expressed in endothelial cells and promotes vascular tube formation. J Cell Physiol 220: 82-90, 2009.

19 Xie Y, Burcu M, Linn DE, Qiu Y and Baer MR: Pim-1 kinase protects P-glycoprotein from degradation and enables its glycosylation and cell surface expression. Mol Pharmacol 78: 310-318, 2010.

20 Halgren TA: Merck molecular force field. I. Basis, form, scope, parameterization, and performance of MMFF94. J Comp Chem 17: 490-519, 1996.

21 Labute P: The generalized Born/volume integral implicit solvent model: Estimation of the free energy of hydration using London dispersion instead of atomic surface area. J Comp Chem 29: 1693-1698, 2008. 
22 Allen JD, Verhoeven E, Domen J, van der Valk M and Berns A: Pim-2 transgene induces lymphoid tumors, exhibiting potent synergy with c-myc. Oncogene 15: 1133-1141, 1997.

23 Paíno T, García-Gómez A, González-Méndez L, San Segundo L, Hernández-García S, López-Iglesias AA, Algarín EM, MartínSánchez M, Corbacho-González D, Ortiz-de-Solórzano C, Corchete L, Gutiérrez NC, Mateos MV, Garayoa M and Ocio EM: The novel pan-PIM kinase inhibitor, PIM447, displays dual anti-myeloma and bone protective effects, and potently synergizes with current standards of care. Clin Cancer Res 23: 225-238, 2016.

24 Koblish H, Shin N, Hall L, Wen X, O'Connor S, Dostalik V, Wang Q, Wang K, Covington M, Marando C, Bowman K, Boer J, Burke K, Zhang K, Feng H, Xue CB, Li YL, Yao W, Huber $\mathrm{R}$, Vaddi $\mathrm{K}$ and Scherle P: Activity of the pan-PIM kinase inhibitor INCB053914 in models of multiple myeloma. Cancer Res 75: 5416, 2015.

25 Keeton EK, McEachern K, Dillman KS, Palakurthi S, Cao Y, Grondine MR, Kaur S, Wang S, Chen Y, Wu A, Shen M, Gibbons FD, Lamb ML, Zheng X, Stone RM, Deangelo DJ, Platanias LC, Dakin LA, Chen H, Lyne PD and Huszar D: AZD1208, a potent and selective pan-Pim kinase inhibitor, demonstrates efficacy in preclinical models of acute myeloid leukemia. Blood 123: 905-913, 2014
26 Chen LS, Redkar S, Bearss D, Wierda WG and Gandhi V: Pim kinase inhibitor, SGI-1776, induces apoptosis in chronic lymphocytic leukemia cells. Blood 114: 4150-4157, 2009.

27 Kirschner AN, Wang J, van der Meer R, Anderson PD, FrancoCoronel OE, Kushner MH, Everett JH, Hameed O, Keeton EK, Ahdesmaki M, Grosskurth SE, Huszar D and Abdulkadir SA: PIM kinase inhibitor AZD1208 for treatment of MYC-driven prostate cancer. J Natl Cancer Inst 107: pii: dju407, 2014.

28 Mumenthaler SM, Ng PY, Hodge A, Bearss D, Berk G, Kanekal S, Redkar S, Taverna P, Agus DB and Jain A: Pharmacologic inhibition of Pim kinases alters prostate cancer cell growth and resensitizes chemoresistant cells to taxanes. Mol Cancer Ther 8: 2882-2893, 2009.
Received May 31, 2017

Revised June 14, 2017

Accepted June 15, 2017 